\title{
Влияние эффекта вынужденного комбинационного рассеяния на дальность работы и чувствительность когерентного рефлектометра
}

\author{
Д.Р. Харасов ${ }^{1,2}$, И.А. Чурилин ${ }^{1,3}$, С.П. Никитин ${ }^{1}$, О.Е. Наний ${ }^{1,4}$, В.Н Трещиков ${ }^{1,5}$ \\ ${ }^{1}$ Группа компаний Т8 \\ ${ }^{2}$ Московский физико-технический институт (государственный университет) \\ ${ }^{3}$ Национальный исследовательский университет «Высшая школа экономики» \\ ${ }^{4}$ Московский государственный университет им. М.В. Ломоносова \\ ${ }^{5}$ Институт радиотехники и электроники им. В.А. Котельникова РАН \\ "E-mail:kharasov@phystech.edu
}

DOI:10.31868/RFL2018.208-210

Оптические рефлектометры разных типов широко используются как для диагностики волоконно-оптических линий связи, так и в качестве распределенных датчиков температуры, механических и акустических воздействий. В импульсных рефлектометрах OTDR (optical timedomain reflectometer) в волокно посылается зондирующий импульс, а полезную информацию получают из рассеянного назад излучения (рассеяние Релея).

Дальность работы различных типов OTDR ограничивается расстояниями порядка 50 км и ее увеличение без существенного усложнения измерительной системы представляет собой трудную задачу. Увеличение дальности действия OTDR путем увеличения мощности светового импульса ограничено искажениями, возникающими из-за воздействия нелинейных эффектов. Исследования влияния нелинейных эффектов на работу когерентных OTDR (Ф-OTDR) проводилось ранее в работах $[1,2]$. В стандартных оптических волокнах огранивающими факторами на мощность импульса в Ф-OTDR является модуляционная неустойчивость $(\mathrm{MH})$ [1-3] и фазовая самомодуляция (ФСМ) [4], которые изменяют спектр излучения, но не меняют форму импульса. В импульсах с формой близкой к прямоугольной ФСМ не вносит существенного вклада. Согласно [5] порог эффектов вынужденного комбинационного рассеяния (ВКР) 1,18 Вт, а порог вынужденного рассеяния Мандельштама - Бриллюэна (ВРМБ) для 100 нс импульса 4,5 Вт, что гораздо выше уровня мощности, при котором начинает проявляется $\mathrm{MH}$ в волокнах с положительной дисперсией: 200-250 мBт[3]. Также в [3] показано, что в волокнах с обратным знаком дисперсии (RDF) MH не развивается. Поэтому ВКР является основным нелинейным эффектом в RDF волокнах, ограничивающим входную мощность импульсов длительностью до 0,4 мкс (для импульсов длительностью более 0,4 мкс порог ВРМБ уже ниже порога ВКР).

В данной работе мы исследовали изменение формы зондирующего импульса и его спектра в волокнах с нормальной и аномальным дисперсией при ВКР, а также влияние ВКР на сигнал рефлектограммы $\Phi$-OTDR. Блок-схема экспериментальной установки показана на Рис. 1. Входная в линию мощность импульса длительностью 200 нс регулировалась эрбиевым волоконным усилителем до 2,7 Вт (см. Рис. 2). Усиленная спонтанная люминесценция (ASE) отсекалась с помощью узкополосного фильтра (полоса пропускания меньше 0,1 нм). Второй фильтр (полоса пропускания 0,8 нм) устанавливался после прохождения тестируемых волокон перед фотодетектором для измерения формы импульса на длине волны излучения лазера 1,55 мкм. Сигнал обратного Релеевского рассеяния через циркулятор и эрбиевый волоконный предусилитель попадает на оптический приёмник, где преобразуется в электрический сигнал. После аналогоцифрового преобразователя (АЦП) электрический сигнал анализируется в блоке обработки сигналов.

На Рис. 3 показаны формы импульсов после прохождения различных волокон: стандартного одномодового волокна G.652 (SMF) с дисперсией +18 пс/нм/км, волокна G.655 (NZDSF) с ненулевой смещенной дисперсией +6 пс/нм/км и RDF-волокна Corning Metrocor ${ }^{\circledR}$ с дисперсией -8 
пс/нм/км. При ВКР во всех волокнах форма импульса сигнала значительно изменяется: центральная часть импульса «проседает».

На Рис. 4 показаны рефлектораммы, измеренные в RDF-волокне до и после развития ВКР. При мощности импульса более 1,8 Вт размах рефлектограммы падает. Соответствующие им оптические спектры показаны на Рис. 5. В спектре в районе 1,55 мкм дополнительных компонент не обнаружено, что говорит об отсутствии ВРМБ и МН. Спектральные компоненты в полосе 16101680 нм соответствуют ВКР. При входной мощности импульса 1,8 Вт разница между пиком импульса и ВКР более 25 дБ, а при 2,79 Вт - порядка 1 дБ.

Нами показано, что максимальная входная мощность импульса в RDF-волокнах ограничена ВКР и составляет 1,8 Вт. Экспериментально выявлено, что при ВКР средний уровень рефлектограммы падает, а также уменьшается её изрезанность. Это обуславливается искривлением формы зондирующего импульса. Так как порог ВКР в RDF на 8,6 и 9,5 дБ больше, чем порог МН в SMF и NZDSF, то при одинаковом затухании среднего уровня рефлектораммы 0,4 дБ/км это эквивалентно дополнительному выигрышу по длине - 21,4 и 23,9 км соответственно.

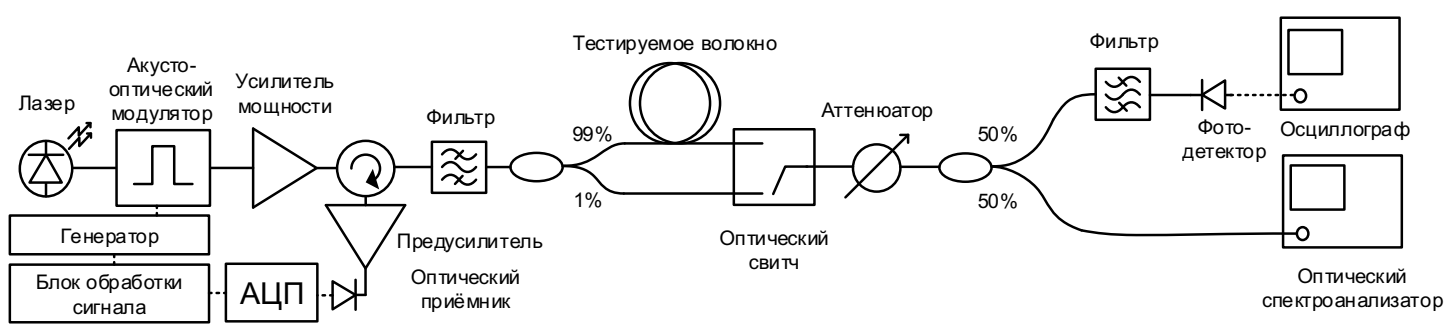

Рис. 1. Блок-схема экспериментальной установки.

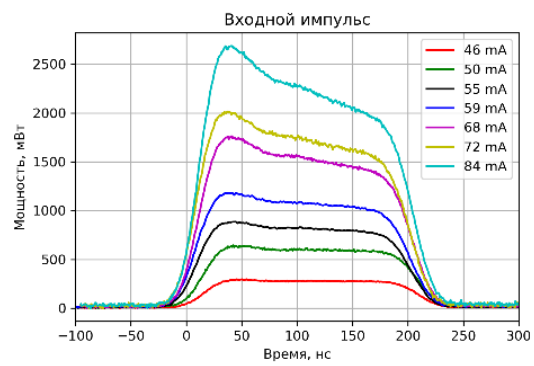

Рис. 2. Форма импульса при разных токах накачки эрбиевого усилителя.
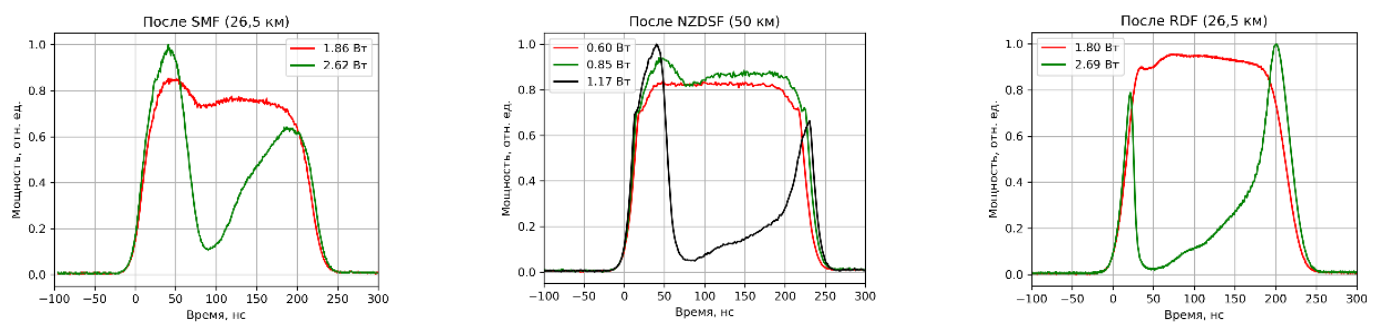

Рис. 3. Форма импульса излучения на длине волны 1,55 мкм после прохождения разных волокон при разных входных мощностях. 


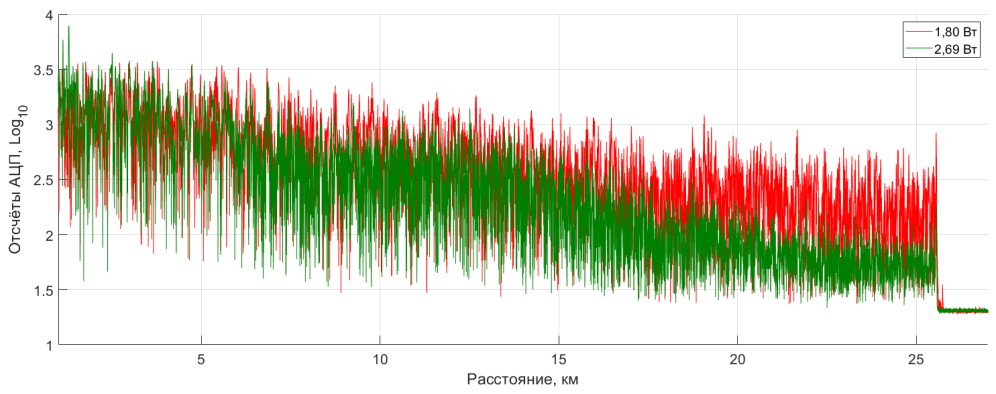

Рис. 4. Рефлектограммы при разных уровнях входной мощности импульса в RDFволокне.
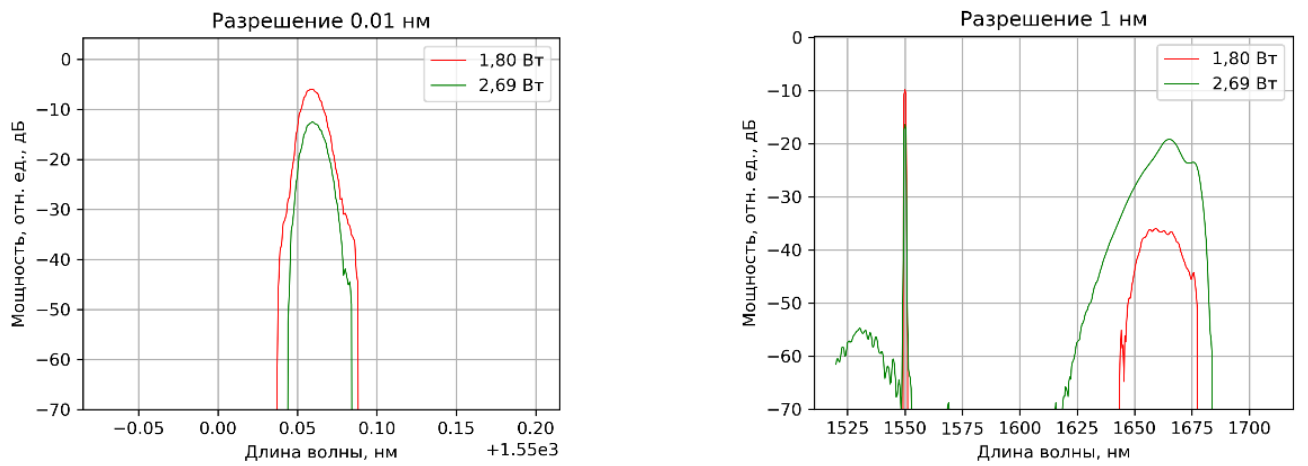

Рис. 5. Спектры после прохождения RDF-волокна при разных уровнях входной мощности: в областях 1550 нм (слева) и 1520-1710 нм (справа).

\section{Литература}

[1] S. A. Babin, et al, Laser Phys. 20.2, 334-340 (2010)

[2] A. E. Ismagulov, et al, Quantum Electron. 39, 765 (2009)

[3] S. P. Nikitin, et al, Laser Phys. 26.10, 105106 (2016)

[4] A. E. Alekseev, et al, Laser Phys. 26.3, 035101 (2016)

[5] H. Izumita, et al, J. Lightwave technology 12.7, 1230-1238 (1994) 